\title{
ANALISIS DESKRIPTIF NILAI RESISTIVITAS AIR AKIBAT RADIASI MATAHARI PADA JENIS WADAH LOGAM
}

\begin{abstract}
Oleh:
Ahmad Abtokhi*

ABSTRAK: Studi analisis nilai resistivitas air sangat penting untuk mengetahui bagaimana kondisi air. Sifat fisika air dapat diketahui melalui nilai hambatan air, dimana perubahan nilai hambatan air merupakan indikator terjadinya perubahan kondisi air. Penelitian ini bertujuan untuk mengetahui pengaruh suhu air akibat radiasi matahari pada wadah/bejana tertentu terhadap nilai resistivitas air. Prinsip dalam penelitian dilakukan dengan cara mengukur nilai tegangan, kuat arus dan perubahan suhu, kemudian menghitung nilai resistivitas air pada setiap bejana. Sampel bejana yang digunakan ada 2 macam, yaitu bejana aluminium dan bejana seng. Ukuran setiap bejana yaitu $10 \mathrm{~cm}$ x $6 \mathrm{~cm} \times 6$ $\mathrm{cm}$ dan diisi air masing-masing $150 \mathrm{ml}$ kemudian dijemur. Data yang diperoleh dari penelitian dianalisis menggunakan analisis deskriptif kuantitatif, yaitu mendeskripsikan grafik hubungan suhu dan resistivitas air. Hasil persamaan regresi untuk bejana aluminium $(\mathrm{y}=-164.9+6.981 \mathrm{x})$ dan bejana seng $(y=-60.63+3.125 x)$. Berdasarkan grafik hasil penelitian menunjukkan bahwa pada wadah seng diperoleh nilai resistivitas air lebih kecil dibandingkan pada wadah aluminium, hal ini disebabkan sifat konduktor dari aluminium yang lebih besar dibandingkan seng. Selain itu sifat fisik warna yang dimiliki oleh seng yang cenderung lebih mengkilap dibandingkan aluminium, sehingga pada penelitian lanjutan perlu mempertimbangkan pewarnaan wadah pada setiap alat uji
\end{abstract}

Kata Kunci: Resistivitas, Radiasi, Wadah.

\section{PENDAHULUAN}

Alam diciptakan oleh Allah SWT dengan ukuran dan takaran tertentu, sebagaimana firman Allah dalam al-Qur'an surat Az-Zukhruf ayat 11. Allah SWT telah menciptakan dan menurunkan air sesuai dengan ukuran dan kadarnya, air yang telah berubah kadar dan ukuran unsur-unsur penyusunnya terkadang mendatangkan pengaruh yang kurang baik terhadap kesehatan manusia. Studi analisis nilai resistivitas air sangat penting untuk mengetahui bagaimana kondisi air, sifat fisika air dapat ditunjukkan melalui nilai hambatan air, dimana perubahan nilai hambatan air merupakan indikator terjadinya perubahan kondisi air.

Secara teoritik air merupakan unsur alami yang mempunyai sifat-sifat kimia maupun fisika didalam struktur atomnya, hal ini dapat dilihat dari pengamatan stetoskop dimana air mempunyai keterkaitan antara unsur atom yang satu dengan unsur atom yang lain yang kemudian membentuk persenyawaan (Sukardjo, 2002). Air adalah substansi kimia dengan rumus kimia $\mathrm{H} 2 \mathrm{O}$, satu melekul air tersusun atas dua atom hidrogen yang terkait secara kovalen pada satu atom oksigen. Air bersifat tidak berwarna, tidak berasa dan tidak berbau pada kondisi standar, yaitu pada tekanan $100 \mathrm{KPa}$ (1 bar) dan temperatur 273,15 K $\left(0^{\circ} \mathrm{C}\right)$. Zat kimia ini merupakan suatu pelarut yang penting, yang memiliki kemampuan

\footnotetext{
*Jurusan Fisika Fakultas Sains dan Teknologi UIN Maliki Malang
} 
untuk melarutkan banyak zat kimia lainnya, seperti garam-garam, gula, asam, beberapa jenis gas dan banyak macam molekul organik (Petrucci, 1985).

Analisis kandungan kimia air sangat mahal karena itu berbagai metode dilakukan untuk melakukan pendekatan dan prediksi untuk mengetahui zat kimia apakah yang mungkin terkandung dalam air berdasarkan sifat fisika air. Sifat fisika air yang digunakan dalam penelitian ini adalah nilai hambatan air dimana perubahan nilai hambatan air merupakan indikator terjadinya perubahan kondisi air (Serway, 1986).

\section{METODE PENELITIAN}

Dalam penelitian ini beberapa alat dan bahan yang digunakan terdiri atas Voltmeter digital, Amperemeter digital, Thermometer digital, Power Supply, Beaker glass, wadah/bejana aluminium, bejana seng, dan Air PDAM daerah Malang.

Perhitungan nilai resistivitas air dilakukan dengan menggunakan rumus $\mathrm{R}=\mathrm{V} / \mathrm{I}, \rho=$ $\mathrm{R}(\mathrm{A} / \mathrm{l})$ dan $\rho=\rho_{0}(1+\alpha \Delta \mathrm{t})$, dengan $\mathrm{R}$ adalah Hambatan listrik, $\rho$ adalah Hambatan jenis (Resistivitas), $\Delta \mathrm{t}$ adalah perubahan suhu. Pengukuran nilai resistivitas air dalam bejana yang berbeda dengan volume air $150 \mathrm{ml}$ dan volume bejana $10 \mathrm{~cm}$ x $6 \mathrm{~cm}$ x $6 \mathrm{~cm}$. Volume air dan perubahan suhu diperlukan untuk mendapatkan nilai resistivitas air. Mekanisme kerja dilakukan dengan menjemur bejana yang telah diisi air $150 \mathrm{ml}$, diukur suhu awal $27.9^{\circ} \mathrm{C}$. Power supply dihidupkan kemudian mencatat perubahan suhu, nilai tegangan dan kuat arus air selama dijemur. Langkah ini diulangi dengan 2 jenis bejana masing-masing jenis bejana 3 buah. Data nilai Resistivitas air dikelompokkan berdasarkan perubahan suhu pada jenis bejana, kemudian mengolah data statistik menggunakan Program Minitab 14. Hasil akhir berupa grafik hubungan nilai resistivitas air terhadap perubahan suhu air akibat pengaruh radiasi matahari serta analysis variansinya (ANOVA).

Penelitian ini menggunakan analisis regresi linear sederhana. Regresi linear sederhana adalah regresi dengan 1 variabel respons dan 1 variabel predictor yang berhubungan linear. Pernyataan matematika model regresi linear sederhana adalah:

$$
Y=\beta 0+\beta 1 x+\varepsilon
$$

Di mana $\beta 0$ dan $\beta 1$ dalah parameter model dan $\varepsilon$ adalah residual model. Taksiran persamaan adalah $y=b 0+b 1 x$, di mana y adalah nilai prediksi atau fitted value, b0 taksiran dari $\beta 0$, dan b1 taksiran dari $\beta 1$. Dalam model regresi, $\varepsilon$ diasumsikan mengikuti distribusi normal dengan rata-rata mendekati 0 (nol) dan standar deviasi tertentu $(\varepsilon \sim \mathrm{N}(\mu$, $\sigma)$ ). Residual mendekati nol berarti jarak antara nilai prediksi dengan nilai sebenarnya seminimal mungkin. Dengan residual semakin mendekati nol, nilai taksiran semakin mendekati nilai sebenarnya. Besar residual inilah yang menjadi kriteria model terbaik (Iriawan, 2006). 


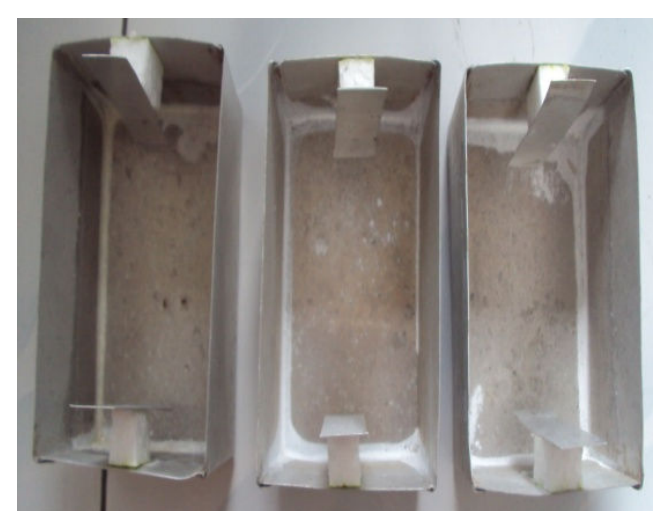

(a)

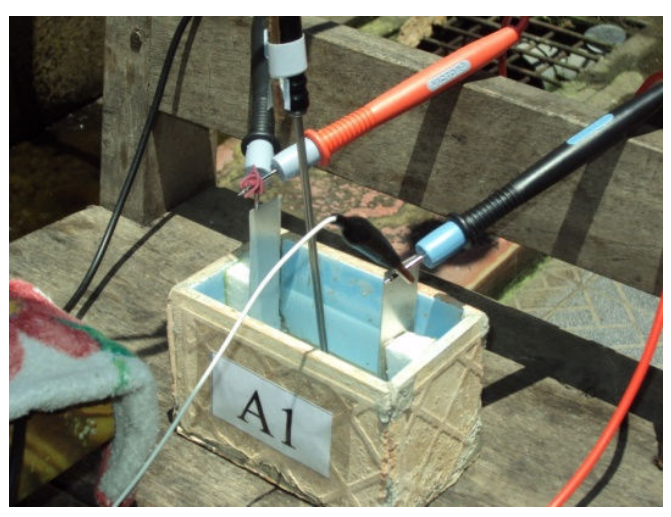

(c)

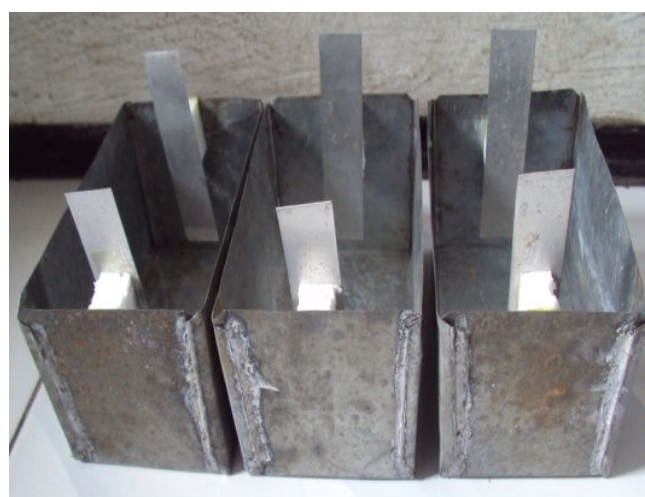

(b)

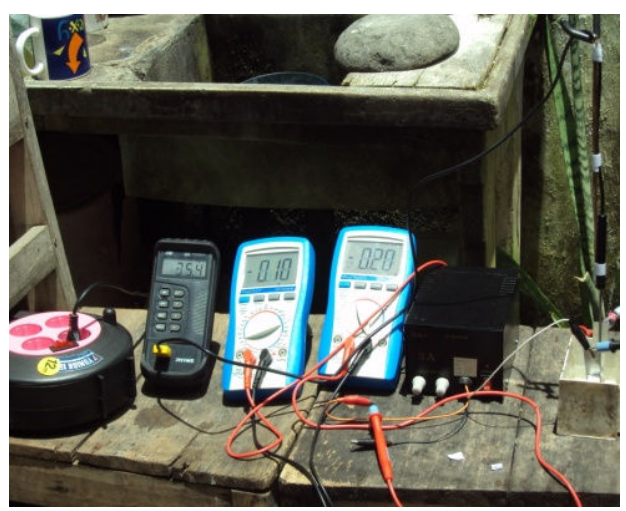

(d)

Gambar 1. Wadah Aluminium (a), Seng (b), dan proses pengambilan data (c dan d)

\section{HASIL DAN PEMBAHASAN}

Nilai rata-rata resistivitas air pada masing-masing bejana aluminium ditunjukkan pada table berikut:

Tabel 1. Data Hubungan Resistivitas dengan Suhu pada Bejana Aluminium

\begin{tabular}{|c|c|c|c|c|c|}
\hline $\mathbf{T}\left({ }^{\circ} \mathbf{C}\right)$ & $\mathbf{\rho} \mathbf{\Omega m}$ & $\mathbf{T}\left({ }^{\circ} \mathbf{C}\right)$ & $\mathbf{\rho} \mathbf{\Omega m}$ & $\mathbf{T}\left({ }^{\circ} \mathbf{C}\right)$ & $\boldsymbol{\rho} \mathbf{\Omega m}$ \\
\hline 28 & 27.39 & 30.7 & 50.36 & 33.4 & 68.45 \\
\hline 28.1 & 28.21 & 30.8 & 54.05 & 33.5 & 69.26 \\
\hline 28.2 & 28.44 & 30.9 & 54.89 & 33.6 & 70.07 \\
\hline 28.3 & 29.86 & 31 & 55.74 & 33.7 & 70.88 \\
\hline 28.4 & 30.69 & 31.1 & 56.58 & 33.8 & 71.69 \\
\hline 28.5 & 31.52 & 31.2 & 57.42 & 33.9 & 72.5 \\
\hline 28.6 & 32.35 & 31.3 & 58.27 & 34 & 72.89 \\
\hline 28.7 & 33.18 & 31.4 & 59.11 & 34.1 & 72.92 \\
\hline 28.8 & 34.01 & 31.5 & 59.95 & 34.2 & 73.12 \\
\hline 28.9 & 34.84 & 31.6 & 60.79 & 34.3 & 73.23 \\
\hline 29 & 35.67 & 31.7 & 61.63 & 34.4 & 73.39 \\
\hline 29.1 & 36.5 & 31.8 & 62.48 & 34.5 & 73.4 \\
\hline & & \multicolumn{3}{|c}{ Created with } \\
\hline
\end{tabular}




\begin{tabular}{|c|c|c|c|c|c|}
\hline $\mathbf{T}\left({ }^{\circ} \mathbf{C}\right)$ & $\mathbf{\rho} \mathbf{\Omega m}$ & $\mathbf{T}\left({ }^{\circ} \mathbf{C}\right)$ & $\mathbf{\rho} \mathbf{\Omega m}$ & $\mathbf{T}\left({ }^{\circ} \mathbf{C}\right)$ & $\boldsymbol{\rho} \mathbf{\Omega m}$ \\
\hline 29.2 & 37.33 & 31.9 & 63.33 & 34.6 & 73.47 \\
\hline 29.3 & 37.37 & 32 & 64.12 & 34.7 & 74.24 \\
\hline 29.4 & 37.45 & 32.1 & 65.92 & 34.8 & 75 \\
\hline 29.5 & 38.24 & 32.2 & 65.96 & 34.9 & 75.76 \\
\hline 29.6 & 39.04 & 32.3 & 65.98 & 35 & 76.53 \\
\hline 29.7 & 39.84 & 32.4 & 66.01 & 35.1 & 77.29 \\
\hline 29.8 & 40.63 & 32.5 & 66.07 & 35.2 & 78.05 \\
\hline 29.9 & 41.43 & 32.6 & 66.13 & 35.3 & 78.82 \\
\hline 30 & 42.19 & 32.7 & 66.28 & 35.4 & 79.58 \\
\hline 30.1 & 43.02 & 32.8 & 66.39 & 35.5 & 80.34 \\
\hline 30.2 & 43.99 & 32.9 & 66.4 & 35.6 & 81.11 \\
\hline 30.3 & 47.17 & 33 & 66.51 & 35.7 & 81.87 \\
\hline 30.4 & 47.97 & 33.1 & 66.6 & 35.8 & 82.63 \\
\hline 30.5 & 48.76 & 33.2 & 66.83 & 35.9 & 83.39 \\
\hline 30.6 & 49.56 & 33.3 & 67.64 & 36 & 84.16 \\
\hline
\end{tabular}

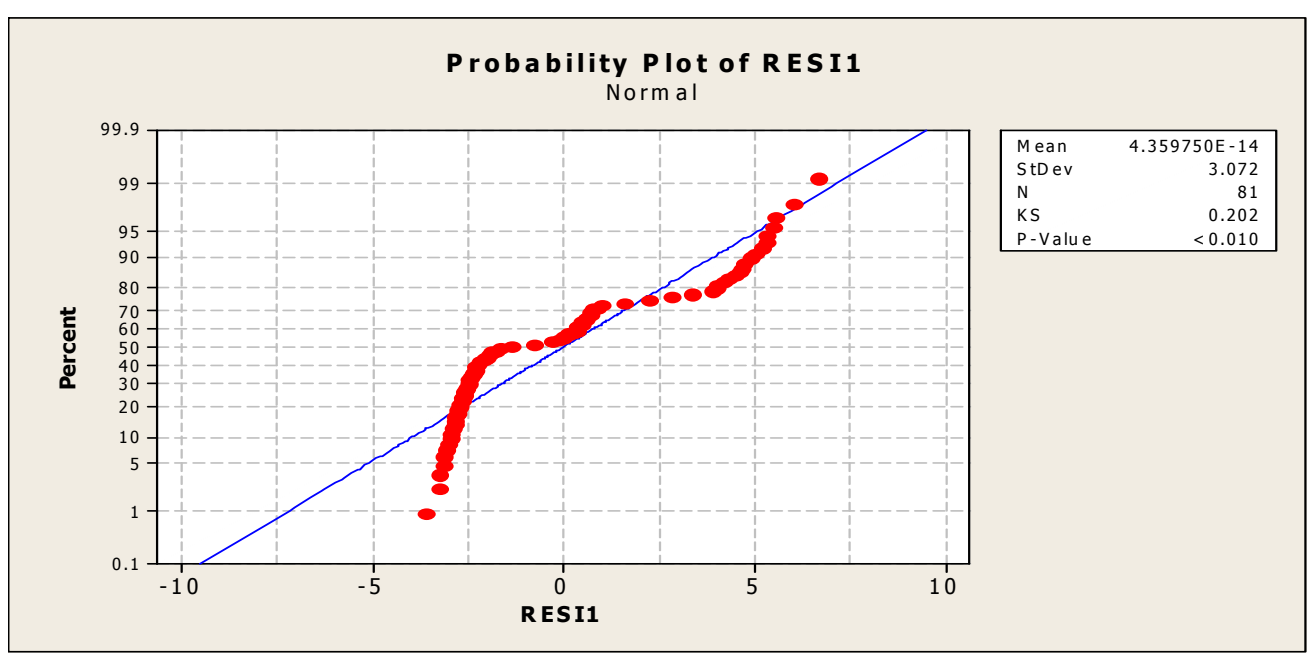

Gambar 2. Plot distribusi normal residual model regresi linear sederhana Aluminium

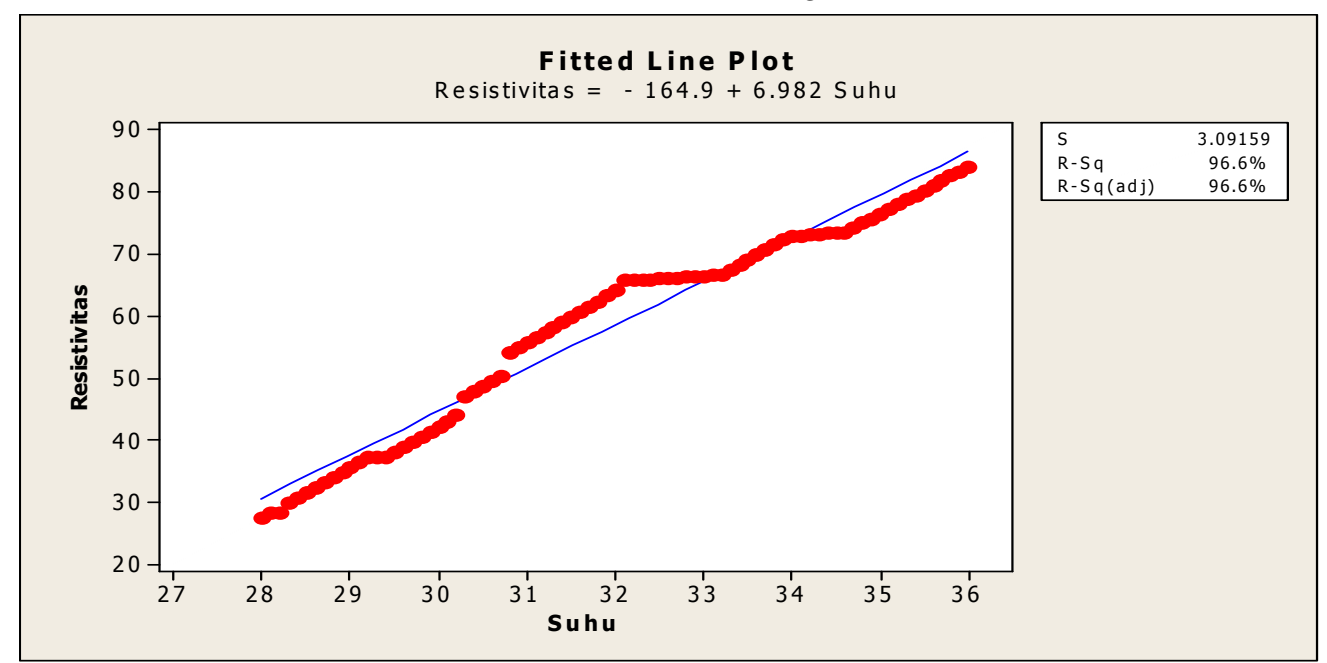

Gambar 3. Grafik Hubungan Resistivitas dengan Suhu pada Bejana Aluminium Created with 
Data nilai resistivitas air dengan nilai perubahan suhu pada bejana aluminium telah mengikuti distribusi normal, sehingga digunakan korelasi regresi linear sederhana. Gambar 3. merupakan grafik hubungan nilai resistivitas air dengan nilai perubahan suhu pada bejana aluminium.

Pada grafik tersebut memperlihatkan persamaan regresi yaitu Resistivitas $=-164.9$ +6.982 Suhu, selain itu juga memperlihatkan nilai standar devisiasi $=3.072$, koefisien determinasi $(\mathrm{R}-\mathrm{Sq})=96.6 \%$ dan $\mathrm{R}-\mathrm{Sq}(\mathrm{Adj})=96.6 \%$.

Aluminium merupakan suatu metal reaktif yang dikenal dengan unsur terpisah termasuk konduktor panas dan elektrik yang baik. Aluminium tahan terhadap korosi karena fenomena pasivasi yaitu pembentukan lapisan pelindung akibat reaksi logam terhadap komponen udara sehingga lapisan tersebut melindungi lapisan dalam logam dari korosi.

Nilai rata-rata resistivitas air pada masing-masing bejana seng ditunjukkan pada tabel berikut:

Tabel 2. Data Hubungan Resistivitas dengan Suhu pada Bejana Seng

\begin{tabular}{|c|c|c|c|c|c|}
\hline $\mathbf{T}\left({ }^{\circ} \mathbf{C}\right)$ & $\rho(\Omega \mathbf{m})$ & $\mathbf{T}\left({ }^{\circ} \mathbf{C}\right)$ & $\rho(\Omega \mathrm{m})$ & $\mathbf{T}\left({ }^{\circ} \mathbf{C}\right)$ & $\rho(\Omega \mathbf{m})$ \\
\hline 28 & 27.13 & 30.7 & 35.15 & 33.4 & 44.66 \\
\hline 28.1 & 28.03 & 30.8 & 35.47 & 33.5 & 44.99 \\
\hline 28.2 & 28.37 & 30.9 & 35.8 & 33.6 & 45.32 \\
\hline 28.3 & 26.76 & 31 & 36.12 & 33.7 & 45.66 \\
\hline 28.4 & 27.07 & 31.1 & 36.45 & 33.8 & 45.98 \\
\hline 28.5 & 27.99 & 31.2 & 36.77 & 33.9 & 46.32 \\
\hline 28.6 & 28.31 & 31.3 & 37.1 & 34 & 46.65 \\
\hline 28.7 & 28.64 & 31.4 & 37.42 & 34.1 & 46.98 \\
\hline 28.8 & 28.96 & 31.5 & 37.75 & 34.2 & 47.31 \\
\hline 28.9 & 29.29 & 31.6 & 38.07 & 34.3 & 47.64 \\
\hline 29 & 29.61 & 31.7 & 38.4 & 34.4 & 47.97 \\
\hline 29.1 & 29.94 & 31.8 & 38.72 & 34.5 & 48.3 \\
\hline 29.2 & 30.26 & 31.9 & 39.05 & 34.6 & 47.84 \\
\hline 29.3 & 30.59 & 32 & 39.37 & 34.7 & 48.16 \\
\hline 29.4 & 30.92 & 32.1 & 39.7 & 34.8 & 48.38 \\
\hline 29.5 & 31.24 & 32.2 & 40.69 & 34.9 & 48.82 \\
\hline 29.6 & 31.56 & 32.3 & 41.03 & 35 & 49.14 \\
\hline 29.7 & 31.89 & 32.4 & 41.35 & 35.1 & 47.5 \\
\hline 29.8 & 32.22 & 32.5 & 42.69 & 35.2 & 47.81 \\
\hline 29.9 & 32.54 & 32.6 & 42.02 & 35.3 & 48.13 \\
\hline 30 & 32.87 & 32.7 & 42.35 & 35.4 & 48.44 \\
\hline
\end{tabular}




\begin{tabular}{|c|c|c|c|c|c|}
\hline $\mathbf{T}\left({ }^{\circ} \mathbf{C}\right)$ & $\boldsymbol{\rho}(\mathbf{\Omega m})$ & $\mathbf{T}\left({ }^{\circ} \mathbf{C}\right)$ & $\boldsymbol{\rho}(\mathbf{\Omega m})$ & $\mathbf{T}\left({ }^{\circ} \mathbf{C}\right)$ & $\boldsymbol{\rho}(\mathbf{\Omega m})$ \\
\hline 30.1 & 33.19 & 32.8 & 42.68 & 35.5 & 48.75 \\
\hline 30.2 & 33.73 & 32.9 & 43.01 & 35.6 & 49.06 \\
\hline 30.3 & 33.84 & 33 & 43.34 & 35.7 & 49.38 \\
\hline 30.4 & 34.17 & 33.1 & 43.67 & 35.8 & 49.69 \\
\hline 30.5 & 34.49 & 33.2 & 44 & 35.9 & 50 \\
\hline 30.6 & 34.82 & 33.3 & 44.33 & 36 & 50.31 \\
\hline
\end{tabular}

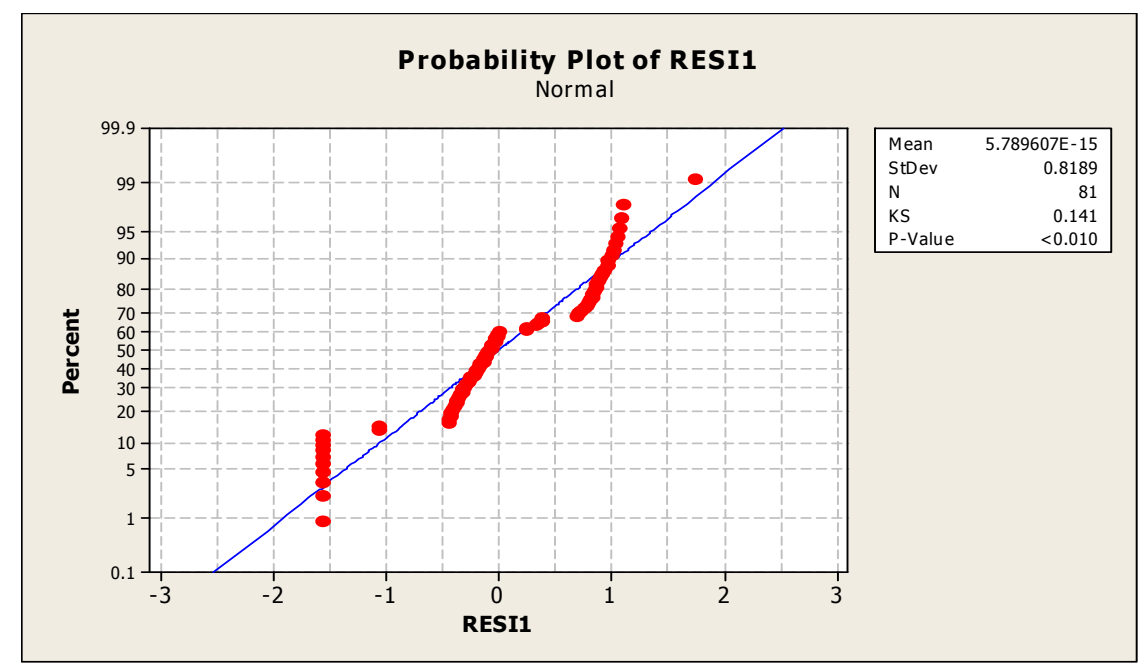

Gambar 4. Plot distribusi normal residual model regresi linear sederhana Seng

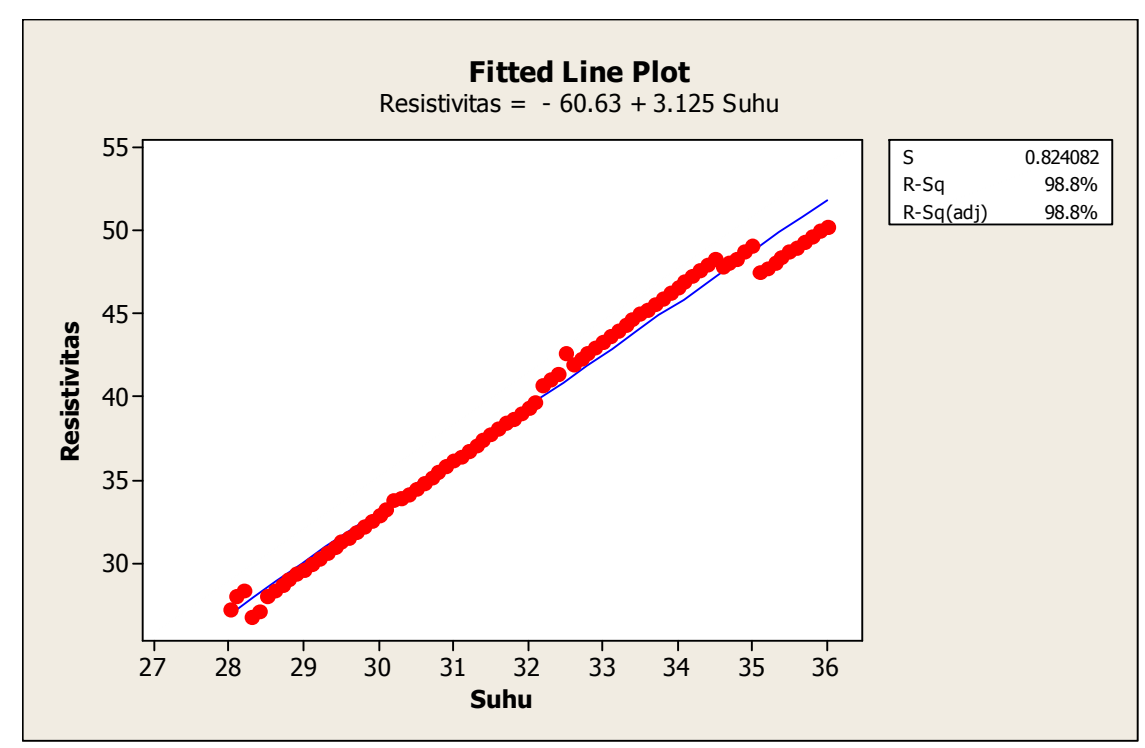

Gambar 5. Hubungan Resistivitas dengan Suhu pada Bejana Seng

Data nilai resistivitas air dengan nilai perubahan suhu pada bejana aluminium telah mengikuti distribusi normal, sehingga korelasi yang digunakan adalah korelasi regresi linear sederhana. Di bawah ini Gambar 5. merupakan grafik hubungan nilai resistivitas air dengan nilai perubahan suhu pada bejana seng. 
Pada grafik tersebut memperlihatkan persamaan regresi yaitu Resistivitas $=-60.63$ +3.125 Suhu, selain itu juga memperlihatkan nilai standar devisiasi $=3.072$, koefisien determinasi $(\mathrm{R}-\mathrm{Sq})=98.8 \%$ dan $\mathrm{R}-\mathrm{Sq}(\mathrm{Adj})=98.8 \%$.

Seng merupakan logam yang berwarna putih kebiruan, berkilau, dan bersifat diamagnetik. Kebanyakan seng mutu komersial tidak berkilau, sedikit kurang padat daripada besi dan berstruktur kristal heksagonal. Seng unsur yang reaktif dan reduktor kuat mampu menghantarkan listrik, nilai resistivitas seng pada suhu 20oC sebesar 59.0 $\Omega$ m. Seng ini keras dan rapuh pada suhu 100 sampai dengan $150^{\circ} \mathrm{C}$, titik lebur $\left(420^{\circ} \mathrm{C}\right)$ dan tidik didih $\left(900^{\circ} \mathrm{C}\right)$ yang relatif rendah. Titik lebur seng merupakan yang terendah di antara semua logam-logam transisi selain raksa dan kadmium.

\section{KESIMPULAN}

Berdasarkan data dan grafik hubungan antara nilai resistivitas air dengan perubahan suhu, pada wadah seng diperoleh nilai resistivitas air lebih kecil dibandingkan pada wadah aluminium, hal ini disebabkan sifat konduktor dari aluminium yang lebih besar dibandingkan seng. Selain itu sifat fisik warna yang dimiliki oleh seng yang cenderung lebih mengkilap dibandingkan aluminium, sehingga pada penelitian lanjutan perlu mempertimbangkan pewarnaan wadah pada setiap alat uji.

\section{DAFTAR PUSTAKA}

Iriawan, N. dan Astuti, S., P. 2006. Mengolah Data Statistik dengan Mudah Menggunakan Minitab 14. Yogyakarta: Andi

Serway, R. A. 1986. Physics for Scientist and Engineers with Modern Physics. New York: Soundners College Publishing

Sukardjo. 2002. Kimia Fisika. Yogyakarta: Penerbit Rineka Cipta

Petrucci, Ralph H. 1985. General Chemistry, Principles, and Modern Applicatio 4th Edition. Colier : Mc. Millan 